\title{
Infantile esotropia: risk factors associated with reoperation
}

\author{
This article was published in the following Dove Press journal: \\ Clinical Ophthalmology \\ 20 October 2016 \\ Number of times this article has been viewed
}

\author{
Adriano Magli' \\ Luca Rombetto 2 \\ Francesco Matarazzo ${ }^{2}$ \\ Roberta Carelli' \\ 'Department of Ophthalmology, \\ Orthoptics and Pediatric \\ Ophthalmology, University of \\ Salerno, Salerno, ${ }^{2}$ Department of \\ Ophthalmology, Federico II University, \\ Naples, Italy
}

\begin{abstract}
The aim of this study was to identify clinical and demographic factors associated with misalignment after first surgery performed on children affected by infantile esotropia to evaluate the reoperation rate. A retrospective study was carried out, analyzing data from 525 children who underwent bilateral medial recti recession, bilateral lateral recti resection, and inferior oblique recession and anteroposition by the same surgeon (AM). Postoperative evaluation included assessment of motor alignment at approximately 3 months, 6 months, 1 year, and 5 years. Statistical analysis was performed with a logistical regression model in which the dependent variable was the presence/absence of reoperation. We found that late surgery (after 3 years of age) and a family history of strabismus are associated with a higher risk of reoperation, while some clinical factors, including some classically associated with worst motor outcome as preoperative angle, dissociated vertical deviation, and amblyopia, did not influence the incidence of reoperation in infantile esotropia. Male patients and patients with hyperopia in preoperative examinations have a significantly decreased reoperation rate.
\end{abstract}

Keywords: infantile esotropia, risk factors, reoperation

\section{Introduction}

Infantile esotropia (IE) is one of the most common forms of pediatric strabismus, with a birth prevalence of 25 per 10,000 newborns. ${ }^{1}$ IE is a large, constant, stable angle esotropia with an onset within the first 6 months of life. ${ }^{2}$ Features associated with IE include alternating esotropia, cross fixation, manifest-latent nystagmus, overacting inferior obliques, dissociated vertical deviation (DVD), and reduced binocular vision. ${ }^{3}$ The final scope of treatment of IE is to align the visual axes to guarantee the development of binocular vision. The focal point of this treatment is surgical intervention. ${ }^{4}$ Nevertheless, due to the lack of randomized trials comparing different surgical strategies for IE, the most effective one and the optimal timing have not yet been univocally defined. ${ }^{3}$ According to scientific literature, surgical alignment of eyes in IE has a variable success rate reported to be from $45 \%$ to $80 \% ;^{5}$ nevertheless, there are still few data regarding risk factors associated with the need of reoperation. The aim of this study was to identify clinical and demographic factors associated with misalignment after first surgery in IE patients and reoperation rate.

\section{Materials and methods}

A retrospective study was carried out analyzing data from 863 patients, examined and operated between 1980 and 2014 by the same surgeon (AM) in the Department of Ophthalmology of "Federico II" University of Naples, in the Department of Ophthalmology, Orthoptics and Pediatric Ophthalmology of University of Salerno, and in two other private centers. 
This study was conducted in accordance with the Declaration of Helsinki and was approved by the Institutional Review Board of the University of Salerno. Written informed consent was obtained from the parents/guardians of all patients.

The study inclusion criteria are the following:

- confirmed IE diagnosis;

- $\quad$ strabismus angle $\geq 30$ prism diopter $(\mathrm{pD})$;

- IE onset by the first 6 months of age;

- absence of central nervous system anomalies and ocular diseases;

- absence of hypermetropia over 3 diopters preoperatively;

- never undergone previous extraocular muscle surgery at the time of examination.

To avoid heterogeneity in surgical approach, we selected patients who underwent bilateral medial recti recession (OO rec MR), bilateral lateral recti resection (OO rec LR), and inferior oblique recession and anteroposition (O rec-ap IO). Patients who underwent other surgical techniques were excluded. In all children, horizontal strabismus and upshoot were diagnosed. Overall, 525 patients were compatible with the established criteria. All patients underwent a preoperative assessment evaluating: sex, familiarity for strabismus, entity of the angle of deviation at nearby Krimsky test (estimated after the total correction of the refractive defect when present), antiamblyopic occlusion therapy, optical correction, lateral recti hypofunction, hypertropia, alphabetical variations ( $\mathrm{V}$ or A variations), DVD, nystagmus, anomalous head positions, amblyopia, and cross fixation. We divided our sample into groups based on the amount of deviation: group $1(30-40 \mathrm{pD})$, group $2(41-59 \mathrm{pD})$, and group $3(\geq 60 \mathrm{pD})$. As the presence of upshoot fell within our inclusion criteria, we considered as a discriminating factor the uni- or bilaterality and the symmetry of it. In children with bilateral symmetric upshoot, the same entity of recession with anteroposition of inferior oblique was performed in both eyes, while asymmetric upshoot required a different entity of recession and anteroposition in the two eyes. Therefore, we evaluated the number of those patients in whom upshoot was not either bilateral and/or symmetric in order to consider the possible different rate of unsuccessful surgery. Furthermore, we divided our sample into three intervals, according to the age at time of surgery: within the 2 years of life, between 2 and 3 years, and over 3 years (before age 5).

Considering the surgical strategy, two main parameters were examined: timing and associated conjunctival recession (performed or not performed).

Postoperative evaluation included assessment of motor alignment approximately at 3 months, 6 months, 1 year, and
5 years. Motor alignment was categorized as "adequate" if alignment was within $10 \mathrm{pD}$ (deviation $>0$ and $\leq 10 \mathrm{pD}$ or deviation $<0$ and $\geq 10 \mathrm{pD}$ ) after a single intervention, or "unsuccessful" if deviation was $\geq 10 \mathrm{pD}$ or $\leq 10 \mathrm{pD}$. Additional muscle surgery and age at reoperation were noted. The same surgeon (AM) decided when reoperation was needed, considering the following criteria: significant residual esotropia or secondary exotropia with a measurable angle $>10 \mathrm{pD}$ reported during different postoperative examinations not influenced by optical correction, sensory state evaluation, appropriate angle follow-up showing angle stability and allowing to give surgical indications, and presence of DVD.

Statistical analysis was performed with a logistical regression model in which the dependent variable was the presence/absence of reoperation, while the predictors have been selected using a forward type model. The model has been adjusted for the "conjunctival recession" variable.

\section{Results}

Preoperative data are shown in Table 1. Esotropia angle before surgery had a range from 30 to $40 \mathrm{pD}$ in 144 children (27.43\%), 41 to $59 \mathrm{pD}$ in 204 patients (38.85\%), and was $>60 \mathrm{pD}$ in $177(33.71 \%)$. All children presented constant esodeviation at two consecutive examinations prior to surgery. In all, 194 children (36.95\%) were operated before the age of 2 years, 228 (43.43\%) between 2 and 3 years, and $103(19.61 \%)$ after 3 years. Conjunctival recession was performed in $65.3 \%$ of cases.

None of the children missed the 3-month postoperative visit, while 17 (3.2\%), 34 (6.5\%), and 117 (22.3\%) missed the 6-month, 1-year, and 5-year postoperative visit.

Table I Preoperative data

\begin{tabular}{ll}
\hline Subject characteristics & $\begin{array}{l}\text { Frequency (\%) } \\
\text { (total } 525 \text { children) }\end{array}$ \\
\hline Sex & $310(59.05)$ \\
Male & $215(40.95)$ \\
Female & $52(9.9)$ \\
Familiarity for strabismus & $349(66.47)$ \\
Occlusion therapy & $473(91.1)$ \\
Optical correction & $335(63.8)$ \\
Lateral recti hypofunction & $63(12)$ \\
Hypertropia & $2(0.38)$ \\
V pattern & $56(10.66)$ \\
A pattern & $151(28.76)$ \\
DVD & $51(9.71)$ \\
Nystagmus & $241(45.9)$ \\
Anomalous head positions & $141(26.86)$ \\
Amblyopia & $179(34.1)$ \\
Cross fixation &
\end{tabular}

Note: Here, we report the presurgical data of 525 patients (and their percentage). Abbreviation: DVD, dissociated vertical deviation. 
Table 2 Motor alignment 3 months, 6 months, I year, and 5 years after surgery

\begin{tabular}{|c|c|c|c|c|}
\hline Postoperative angle & 3 months & 6 months & I year & 5 years \\
\hline$\leq 10 \mathrm{pD}$ & $87 / 525(16.57)$ & $70 / 508(13.78)$ & $82 / 491$ (16.70) & $42 / 408(10.29)$ \\
\hline Between -10 and +10 pD & $374 / 525(71.23)$ & $381 / 508(75)$ & $339 / 491(69.04)$ & $332 / 408$ (8I.37) \\
\hline$\geq 10 \mathrm{pD}$ & $64 / 525(12.20)$ & $57 / 508(11.22)$ & $70 / 491$ (14.26) & $34 / 408(8.33)$ \\
\hline Missing & 0 & 17 & 34 & 117 \\
\hline
\end{tabular}

Note: Here, we report the postsurgical deviation angle based on the quantity and the elapsed time after surgery (\%).

Abbreviation: $\mathrm{pD}$, prism diopter.

The percentage of patients lost at follow-up considerably increased 5 years after surgery.

Adequate alignment (within $10 \mathrm{pD}$ of orthotropia) was achieved for $71.2 \%$ to $81.3 \%$ of children at the 3-month, 6-month, 1-year, and 5-year postoperative visit (Table 2).

Regarding reoperation, 50 children $(9.52 \%)$ underwent additional surgery at 2.93 years after the first operation, at a mean age of 6.54 years. Fourteen reoperations were performed in group 1, 17 reoperations in group 2, while 19 second surgeries were recorded in group 3.

A total of 35 children needed additional surgery for consecutive exotropia while 15 for residual esotropia.

Concerning statistical analysis, in a multiple-variable logistic regression model, older age and family history of strabismus were associated with an increased probability of reoperation, while male sex and hypertropia were associated with a decreased probability of reoperation (Table 3 ).

Antiamblyopic occlusion therapy, optical correction, lateral recti hypofunction, alphabetical variations (V or A variations), absence of bilateral symmetric upshoot, DVD, nystagmus, anomalous head positions, amblyopia, and cross fixation were not associated with reoperation.

\section{Discussion}

Although reoperation is one of the most common complications of IE surgery, only a few studies have identified factors associated with unsuccessful postoperative motor alignment.

The timing of initial surgery is one of the most important clinical factors associated with motor and sensory outcome.
Our study confirms, as reported by recent studies, ${ }^{6,7}$ that surgery performed after the age of 3 years increases the risk of unsuccessful alignment at first operation; in fact, children operated after 3 years of age have a significant increase of risk of reoperation (odds ratio $[\mathrm{OR}] 5.4 ; P<0.001$ ). Instead, surgery performed between 2 and 3 years of life is not significantly associated with a higher risk of need of reoperation compared with surgery performed before 2 years old (OR 1.616; $P=0.230$ ). Our results are coherent with other studies that indicate late surgery as cause of unsatisfactory motor outcome. ${ }^{6-9}$

Another important parameter to be considered is stereopsis. As suggested by other studies, ${ }^{6,7}$ IE patients who are operated late generally achieve worse stereopsis, resulting in poorer motor alignment.

The current study does not investigate the long-term prevalence of stereopsis after surgery. However, we have evaluated sensory postoperative outcomes in another in-press study on a similar IE patient cohort. The data by our multivariate analysis report that children operated after 2 years of age were 0.4 times less likely to obtain binocular single vision (BSV) compared with children operated before 2 years of age (adjusted odds ratio [AOR] 0.38, 95\% confidence interval $0.17-0.89, P=0.025) .{ }^{10}$

Accordingly, several clinical studies showed that surgical realignment of the eyes during the first 2 years of life is associated with better sensory outcome than surgical alignment performed after 2 years of life. ${ }^{11,12}$

While in North America there is a tendency to perform surgery for IE usually before 12 months of life (early surgery),

Table 3 Odds ratio (OR) and 95\% confidence intervals (Cls) obtained by logistical regression model

\begin{tabular}{|c|c|c|c|c|}
\hline \multirow[t]{2}{*}{ Subject characteristics } & \multirow[t]{2}{*}{$P$-value } & \multirow[t]{2}{*}{ OR } & \multicolumn{2}{|c|}{$95 \% \mathrm{Cl}$ for OR } \\
\hline & & & Lower & Upper \\
\hline Male sex & 0.003 & 0.375 & 0.196 & 0.719 \\
\hline Family history & 0.042 & 2.408 & 1.034 & 5.61 \\
\hline Hypertropia & 0.025 & 0.271 & 0.087 & 0.852 \\
\hline Age at first surgery ( $<2$ years) & 0.000 & & & \\
\hline Age at first surgery ( $2-3$ years) & 0.230 & 1.616 & 0.739 & 3.534 \\
\hline Age at first surgery ( $>3$ years) & 0.000 & 5.4 & 2.343 & 12.445 \\
\hline
\end{tabular}

Note: Here, we report several parameters based on the $\mathrm{OR}$ and $\mathrm{Cl}$ to evaluate the probability of a reoperation. 
in Europe it is more often delayed till 12-36 months (standard surgery). In our practice, we do not operate children before 11 months due to the higher frequency of reoperation documented for early surgery. ${ }^{13}$ According to our data, inferior oblique hyperfunction evaluation is rarely accurate in very small children. Furthermore, potentially incomplete amblyopia treatment, angle instability, and delayed maturation of sensorimotor system, and possibility of at least partially spontaneous resolution justify our choice.

In our study, $50(9.52 \%)$ children had a reoperation. Data from the literature report reoperation rate as variable. A reoperation rate of $34 \%$ was found by Trigler and Siatkowski, ${ }^{14}$ $16 \%-21 \%$ by Foster et al, ${ }^{15} 28 \%$ by Maruo et al, ${ }^{16}$ and $20 \%$ by Teller et al. ${ }^{17}$ In the "Early versus Late Infantile Strabismus Surgery Study", ${ }^{13}$ patients in an early-surgery cohort had 1.18 surgeries per patient compared with 0.99 surgeries per patient in late-surgery cohort. Simonsz and Eijkemans, ${ }^{18}$ in a recent and detailed study, analyzed the rate of reoperation and rate of spontaneous resolution in IE. The meta-regression analysis, including 12 studies, has shown reoperations rates between $60 \%$ and $80 \%$ for children first operated approximately at 1 year of age and $\sim 25 \%$ for children operated around at 4 years of age. The authors conclude accordingly that the benefit of early surgery for gross binocular vision is balanced by a higher reoperation rate.

Concerning the operation type, comparing our experience with literature data, we can state that the surgical approach of bilateral medial recti recession, bilateral lateral recti resection, and inferior obliqui recession and anteroposition guarantee a good surgical result. ${ }^{19}$

Another factor to evaluate is the role of family history of strabismus in IE. In the literature, frequency of family history of strabismus is reported to be between $6 \%$ and $74 \% .^{13,14,20}$ In our patient cohort, the percentage of positive family history of strabismus is relatively low (9.9\%). Our statistical model shows a higher risk of unsuccessful motor alignment at first surgery in children with a family history for strabismus (OR 2.4; $P=0.042$ ). We can speculate about the existence of genetically determined strabismogenic factors influencing both development of strabismus and treatment failure.

Unlike previous studies, we found a lower risk of reoperation in male sex (OR $0.37 ; P=0.003$ ). In our sample, the percentage of male sex in the group of children requiring just one operation is $61 \%$ while it is $40 \%$ in the group of children who underwent reoperation. Trigler and Siatkowski ${ }^{14}$ found a similar frequency of male sex, 55\% in the group requiring only one operation, $45 \%$ in the group requiring two or more operations, but the difference was not statistically significant.
Presence of hypertropia at presurgical evaluations affects motor outcome determining a significant lower risk of reoperation (OR $0.27 ; P=0.025$ ). This finding is probably justified by the fact that in some children hypertropia may appear at a later stage, after the first intervention has been performed. Our study is not sufficient to provide data about the time of presentation of motor defects and relate the latter to the effect on treatment outcome.

Smaller preoperative angles are usually associated with a favorable motor outcome. ${ }^{14}$ In contrast with this study, we found that the entity of preoperative angle does not affect the risk of reoperation.

Deviation variability, antiamblyopic occlusion therapy, optical correction, lateral recti hypofunction, alphabetical variations (V or A variations), absence of bilateral symmetric upshoot, DVD, nystagmus, anomalous head positions, amblyopia, and cross fixation were not associated with the need of reoperation.

\section{Conclusion}

We found that demographic factors, such as sex and family strabismus history, are associated with a higher risk of reoperation. On the other hand, some clinical features, including a few factors classically associated with worst motor outcome, such as preoperative angle, DVD, and amblyopia, did not influence, in our cohort, the incidence of reoperation. Patients with hypertropia in preoperative examinations have a significantly decreased reoperation rate. Concerning the timing of surgery, the first operation after 36 months of life is associated with a higher frequency of reoperation than children operated before 24 months of life; on the basis of the earlier considerations concerning binocular vision and reoperation rate, we suggest performing IE surgery between 12 and 24 months to achieve an optimal motor alignment.

\section{Disclosure}

The authors report no conflicts of interest in this work.

\section{References}

1. Louwagie CR, Diehl NN, Greenberg AE, Mohney BG. Is the incidence of infantile esotropia declining?: a population-based study from Olmsted County, Minnesota, 1965 to 1994. Arch Ophthalmol. 2009; 127(2):200-203.

2. Simonsz HJ, Kolling GH. Best age for surgery for infantile esotropia. Eur J Paediatr Neurol. 2011;15(3):205-208.

3. Elliott $\mathrm{S}$, Shafiq A. Interventions for infantile esotropia. Cochrane Database Syst Rev. 2013;7:CD004917.

4. Hug D. Management of intantile esotropia. Curr Opin Ophthalmol. 2015; 26(5):371-374.

5. Louwagie CR, Diehl NN, Greenberg AE, Mohney BG. Long-term follow-up of congenital esotropia in a population-based cohort. J AAPOS. 2009;13(1):8-12. 
6. Ing MR. Early surgical alignment for congenital esotropia. Trans Am Ophthalmol Soc. 1981;79:625-663.

7. Birch EE, Fawcett S, Stager DR. Why does early surgical alignment improve stereoacuity outcomes in infantile esotropia? $J$ AAPOS. 2000;4(1):10-14.

8. Shauly Y, Prager TC, Mazow ML. Clinical characteristics and longterm postoperative results of infantile esotropia. Am J Ophthalmol. 1994; 117(2):183-189.

9. Zak TA, Morin JD. Early surgery for infantile esotropia: results and influence of age upon results. Can J Ophthalmol. 1982;17(5):213-218.

10. Magli A, Carelli R, Esposito F, Bruzzese D. Essential infantile esotropia: postoperative sensory outcomes of strabismus surgery. Semin Ophthalmol. Epub 2016 Jul 1:1-9.

11. Birch EE, Stager DR, Everett ME. Random dot stereoacuity following surgical correction of infantile esotropia. J Pediatr Ophthalmol Strabismus. 1995;32(4):231-235.

12. Pediatric Eye Disease Investigator Group. Spontaneous resolution of early-onset esotropia: experience of the Congenital Esotropia Observational Study. Am J Ophthalmol. 2002;133(1):109-118.

13. Simonsz HJ, Kolling GH, Unnebrink K. Final report of the early vs. late infantile strabismus surgery study (ELISSS), a controlled, prospective, multicenter study. Strabismus. 2005;13(4):169-199.
14. Trigler L, Siatkowski RM. Factors associated with horizontal reoperation in infantile esotropia. J AAPOS. 2002;6(1):15-20.

15. Foster RS, Paul TO, Jampolsky A. Mangement of infantile esotropia. Am J Ophthalmol. 1976;82(2):291-299.

16. Maruo T, Kubota N, Sakaue T, Usui C. Esotropia surgery in children: Long term outcome regarding changes in binocular alignment; a study of 956 cases. Binocul Vis Strabismus Q. 2000;15(3):213-220.

17. Teller J, Savir H, Yelin N, Cohen R, Leviav A, Elstin R. Late results of surgery for congenital esotropia. Metab Pediatr Syst Ophthalmol. 1988;11(3): $115-118$.

18. Simonsz HJ, Eijkemans MJC. Predictive value of age, amd refraction on rate of reoperation and rate of spontaneous resolution in infantile esotropia. Strabismus. 2010;18(3):87-97.

19. Magli A, Carelli R, Matarazzo F, Bruzzese D. Essential infantile esotropia: postoperative motor outcomes and inferential analysis of strabismus surgery. BMC Ophthalmol. 2014;14:35.

20. Pediatric Eye Disease Investigator Group. The clinical spectrum of early-onset esotropia: experience of the Congenital Esotropia Observational Study. Am J Ophthalmol. 2002;133(1):102-108.
Clinical Ophthalmology

\section{Publish your work in this journal}

Clinical Ophthalmology is an international, peer-reviewed journa covering all subspecialties within ophthalmology. Key topics include: Optometry; Visual science; Pharmacology and drug therapy in eye diseases; Basic Sciences; Primary and Secondary eye care; Patient Safety and Quality of Care Improvements. This journal is indexed on

Submit your manuscript here: http://www.dovepress.com/clinical-ophthalmology-journal

\section{Dovepress}

PubMed Central and CAS, and is the official journal of The Society of Clinical Ophthalmology (SCO). The manuscript management system is completely online and includes a very quick and fair peer-review system, which is all easy to use. Visit http://www.dovepress.com/ testimonials.php to read real quotes from published authors. 